\title{
Estudio sobre los parámetros de impresión para mejorar la inyección por goteo-sobre- demanda de $\mathrm{ZnO}$ y $\mathrm{Al}: \mathrm{ZnO}$
}

\author{
Study on printing parameters to improve the drop-on-demand inkjet of $\mathrm{ZnO}$ and \\ $\mathrm{Al}: \mathrm{ZnO}$ \\ S. I. Garduño-Vértiz (iDa,*, J. Fajardo-Cornejo ${ }^{b}$, V. Rodríguez-Lugo iD a , M. Estrada del Cueto iD \\ a Área Académica de Ciencias de la Tierra y Materiales, Instituto de Ciencias Básicas e Ingeniería, Universidad Autónoma del Estado de Hidalgo, 42184, Mineral de la \\ Reforma, Hidalgo, México. \\ ${ }^{b}$ Sección de Electrónica del Estado Sólido, Departamento de Ingeniería Eléctrica, CINVESTAV, Instituto Politécnico Nacional, 07360, CDMX, México.
}

\begin{abstract}
Resumen
Este estudio propone la optimización de las condiciones y parámetros de impresión por inyección piezoeléctrica de tintas basadas en óxido de zinc $(\mathrm{ZnO})$ y óxido de zinc dopado con aluminio (Al:ZnO). Se imprimieron patrones con distinta resolución bajo condiciones y parámetros de eyección continua de tintas comerciales que poseen propiedades reológicas específicas para esta técnica. Estas tintas consisten en $\mathrm{ZnO}$ o $\mathrm{Al}: \mathrm{ZnO}$ en forma de nanopartículas, las cuales están dispersadas en una combinación de alcoholes. Los patrones impresos son caracterizados mediante las técnicas de microscopia de fuerza atómica, elipsometría y microscopía óptica para determinar la variación en su morfología, espesor y uniformidad, respectivamente. Los resultados obtenidos dependen de la resolución y son la evidencia para determinar las condiciones y parámetros óptimos que permitan el traslape entre patrones impresos de otros materiales, de tal forma que se considere su uso en la fabricación de dispositivos semiconductores totalmente impresos.
\end{abstract}

Palabras Clave:

Impresión por inyección de tinta, Goteo-sobre-demanda, Imprimibilidad, ZnO impreso, Al:ZnO impreso, Patrones impresos uniformes.

\begin{abstract}
This study proposes the optimization for the inkjet printing parameters and conditions of inks based in zinc oxide ( $\mathrm{ZnO}$ ) or zinc oxide doped with aluminium $(\mathrm{Al}: \mathrm{ZnO})$ processed in solution. Hereby, patterns are printed with different resolution, under continuous ejection conditions and parameters of commercially available inks, which poses specific rheological properties for this technique. The used inks consist in $\mathrm{ZnO}$ or $\mathrm{Al}: \mathrm{ZnO}$ in the form of nanoparticles, that are dispersed in an alcohols combination. The printed patterns are characterized by the techniques of atomic force microscopy, ellipsometry and optical microscopy to determine the variation on its morphology, thickness, and uniformity, respectively. Predominantly, the obtained results depend on the configured resolution, and they are important evidence to determine the optimal conditions and parameters that allow the possible overlap between printed patterns of other different materials, such that it is considered its use in the fabrication of fully printed semiconductor devices.
\end{abstract}

Keywords:

Inkjet printing, Drop-on-demand, Printability, Printed $\mathrm{ZnO}$, Printed $\mathrm{Al}: \mathrm{ZnO}$, Uniform printed patterns.

\section{Introducción}

Recientemente, diferentes trabajos de investigación sobre la técnica de impresión por inyección de tinta (IJP) han enfocado esfuerzos importantes, esto debido a las ventajas que ofrece para la fabricación de dispositivos electrónicos de bajo costo, tales como (Chu et al., 2019), (Matavž and Malič, 2018), (Park et al., 2019),
(Sowade et al., 2016): el depósito directo de materiales en patrones; evitar la fotolitografía y el decapado, que son procesos convencionales para la manufactura de circuitos integrados en la tecnología del silicio; no requiere equipos que operan en condiciones de alto vacío, como las técnicas de depósito en fase gaseosa, instalaciones especializadas (cleanroom) o atmósferas inertes; además, ofrece el procesamiento a baja temperatura para la fabricación de dispositivos semiconductores $\left(\leq 60^{\circ} \mathrm{C}\right)$. Dichas ventajas

\footnotetext{
*Autor para la correspondencia: salvador_garduno@uaeh.edu.mx Lugo),mestrada@yahoo.com (Magali Estrada del Cueto).

Correo electrónico: salvador_garduno@uaeh.edu.mx (Salvador Iván Garduño-Vértiz), jfajardo@cinvestav.mx (Josué Fajardo-Cornejo), venturar@uaeh.edu.mx (Ventura Rodríguez- 
hacen que esta técnica sea compatible con el desarrollo de la electrónica flexible y transparente, aunque aún existen desafíos importantes para la fabricación de dispositivos semiconductores de película delgada que sean impresos completamente (Lim et al., 2014), (Park et al., 2019), (Sanchez et al., 2018), entre estos destaca que aún no se ha reportado una descripción detallada del proceso de IJP y las variaciones que se generan en la morfología, el grosor y la uniformidad del área en los patrones impresos, lo cual permita mejorar el desempeño de los dispositivos electrónicos. En este sentido, se ha reportado la obtención de dispositivos basados en óxidos metálicos semiconductores (MOS), incluyendo la IJP en su secuencia tecnológica de fabricación (Carlos et al., 2021), (Li et al., 2017), (Ning et al., 2017), (Secor et al., 2016).

\subsection{Tintas basadas en óxido de zinc.}

Entre los MOS, el óxido de zinc $(\mathrm{ZnO})$ se ha establecido como uno de los más importantes y versátiles tecnológicamente, en especial para el desarrollo de aplicaciones basadas en materiales procesados en solución y que emplean técnicas de impresión (Arrabito et al., 2020). Esto se debe a que el $\mathrm{ZnO}$ presenta diferentes ventajas, por ejemplo (Arrabito et al., 2020), (Kandpal et al., 2016): es posible obtenerlo de forma cristalina, aunque se deposite a baja temperatura en distintos tipos de sustratos, incluyendo rígidos, transparentes y flexibles; además, es un semiconductor de transiciones directas entre bandas de energía, cuyo ancho de banda prohibida se reporta con un valor promedio de $\sim 3.3$ eV, lo cual depende de la técnica empleada para su depósito, por lo que presenta una transmitancia óptica $>80 \%$. En comparación con el $\mathrm{ZnO}$, aunque el uso del óxido compuesto de Indio-GalioZinc (IGZO) como capa activa en transistores de película delgada (TFTs) ha demostrado proveer mayor movilidad por efecto de campo y estabilidad al estrés por polarización/iluminación, el procedimiento para sintetizar en solución al IGZO puede ser un método complejo y, una vez depositado, requerir de un recocido a una temperatura $>300^{\circ} \mathrm{C}$ (Kim et al., 2009). Hasta el momento, incluso el IGZO procesado en solución no se encuentra comercialmente disponible para su uso mediante una impresora de inyección piezoeléctrica de tinta.

Adicionalmente, ha incrementado el interés en cuanto a la investigación de materiales transparentes conductivos, los cuales se han implementado en la estructura de diferentes dispositivos semiconductores, como diodos emisores de luz (Chang et al., 2003), en celdas solares (Wang et al., 2013) y en circuitos electrónicos para la fabricación de pantallas planas (Gordon, 2000). Entre los óxidos conductores transparentes (TCO), uno de los más comunes es el óxido de Indio/Estaño (ITO) usado como electrodo de contacto (Hashemi et al., 2020). Sin embargo, tanto la demanda del Indio como su escasez natural resultan en un notable aumento del costo de este elemento y, por lo tanto, de los materiales que lo componen (Hashemi et al., 2020). Por tales motivos, se realizan diferentes estudios que permitan sustituir el ITO por algún otro TCO libre de Indio, con el propósito de continuar el desarrollo de aplicaciones flexibles y transparentes. El dopaje del $\mathrm{ZnO}$ con aluminio $(\mathrm{Al}: \mathrm{ZnO})$ ha sido considerado como una alternativa de TCO a las películas de ITO y ha recibido especial atención dado que no es tóxico, a la abundancia natural de sus elementos, presenta propiedades eléctricas y ópticas como una resistividad de 25.4 $\mathrm{m} \Omega \cdot \mathrm{cm}$, una concentración de portadores de $\sim 10^{19} \mathrm{~cm}^{-3}$ y una transmitancia óptica $>80 \%$ dentro del espectro electromagnético de luz visible; además, es compatible con diferentes métodos de depósito convencionales (Gutiérrez et al., 2013), (Song, et al., 2010), (Vernieuwe et al., 2017). Se ha reportado la variación de la resistividad eléctrica y la morfología en patrones impresos de $\mathrm{Al}: \mathrm{ZnO}$, sólo como resultado de la temperatura y de la atmósfera empleada en un proceso de tratamiento térmico (Vernieuwe et al., 2017), pero sin considerar que también se inducen cambios en las propiedades de los patrones mediante de las condiciones y parámetros del proceso de impresión.

\subsection{Imprimibilidad.}

El término imprimibilidad se define como el conjunto de propiedades fisicoquímicas de la tinta que cumplen con criterios propuestos para lograr su expulsión o eyección, mediante el uso de impresoras de DoD, de forma continua, uniforme, repetible y sin gotas satélite (Lin et al., 2015), (Du et al., 2018). En este sentido, se deben determinar los números adimensionales de Reynolds $(R e=v \rho a / \eta)$, Weber $\left(W e=v^{2} \rho a / \gamma\right)$, Ohnersorge $(O h=\sqrt{W e} / R e)$ y el número $Z=1 / O h$, para cuantificar la imprimibilidad de una tinta, y establecer si los mecanismos de formación y expulsión de ésta permiten su uso en impresoras DoD (Fromm, 1984); así como la interacción de las gotas eyectadas con la superficie de un sólido (Martin et al., 2008). Donde $\rho, \eta$ y $\gamma$ son la densidad, la viscosidad y la tensión superficial de la tinta, respectivamente, que es expulsada a una cierta velocidad $(v)$ desde un inyector con diámetro $(a)$ definido. Sin embargo, los investigadores que han propuesto los criterios para establecer cuantitativamente la imprimibilidad de una tinta sólo consideran solventes comúnmente utilizados para la síntesis de las tintas; por ejemplo, el agua deionizada, el etilenglicol, el glicerol, el isopropanol, etc., pero sin que el solvente contenga algún material sólido en forma de nanopartículas (Krainer et al., 2020), (Lee et al., 2012), (Liu y Derby, 2019), (Martin et al., 2008), (Schiaffino y Sonin, 1997).

Actualmente, son pocos los materiales procesados en solución que están disponibles de forma comercial y que cumplen con propiedades reológicas compatibles y adecuadas para su uso por la técnica de impresión por inyección piezoeléctrica de tinta; es decir, aquellas características que habilitan la generación de gotas de manera estable para una impresión continua y uniforme. Además, aquellos trabajos que reportan la fabricación de dispositivos semiconductores de capa delgada, utilizando parcialmente la impresión por inyección de tinta, no presentan un estudio sobre las condiciones de impresión de los materiales impresos y el impacto que esto puede tener sobre su desempeño. Por tales motivos, en este estudio se propone optimizar las condiciones y parámetros del proceso de impresión por inyección piezoeléctrica de tintas comerciales basadas en óxido de zinc, mostrando la importancia de su apropiada configuración para mantener la eyección de gotas de tinta de forma continua, uniforme y repetible durante la impresión, lo cual permita controlar la morfología, el espesor y la uniformidad del área de los patrones impresos.

\section{Procedimiento experimental.}

Las tintas utilizadas a través del proceso de impresión de patrones fueron obtenidas de Nanograde Ltd. y consisten en $\mathrm{ZnO}$ y $\mathrm{Al}: \mathrm{ZnO}$ en forma de nanopartículas (nPs) dispersadas en isopropanol y propilenglicol al $2.5 \%$ en peso. Además, el tamaño de estas nPs está entre $8 \mathrm{~nm}$ y $16 \mathrm{~nm}$. Las propiedades reológicas de las tintas que proporciona el fabricante comprenden una viscosidad en un rango entre 8 y $16 \mathrm{mPa} \cdot \mathrm{s}$, una tensión superficial de 24 a 48 $\mathrm{mJ} / \mathrm{m}^{2}$, y una densidad en un rango de 900 a $940 \mathrm{~kg} / \mathrm{m}^{3}$, las cuales son apropiadas para la impresión por inyección de tinta.

\subsection{Consideraciones previas al proceso de impresión.}

Antes de llenar los cartuchos con una capacidad de eyectar un volumen de $1 \mathrm{pL}$, las tintas fueron agitadas en un equipo de limpieza ultrasónico (SperScientific) a una frecuencia de $42 \mathrm{kHz}$ du- 
rante 10 min para romper los aglomerados que se hubiesen formado de las nPs dispersadas (Sigma Aldrich, 2021). Además, las tintas fueron filtradas a través de una membrana de politetrafluoroetileno de $0.2 \mu \mathrm{m}$ para evitar agregados de mayor tamaño que el poro del filtro (Li et al., 2019).

A priori al proceso de impresión, se usaron sustratos de silicio tipo- $p$ con un área de $2.5 \times 2.5 \mathrm{~cm}^{2}$ como soporte mecánico, que fueron sometidos a un proceso de limpieza estándar tipo RCA, que se utiliza en la fabricación de dispositivos semiconductores para eliminar impurezas orgánicas y iónicas que alteren el desempeño del dispositivo (Kern, 1993), pero también para producir una superficie hidrofílica para su apropiada humectación con las tintas.

\subsection{Proceso de impresión y tratamiento térmico.}

Usando la impresora DIMATIX (DMP-2800), patrones cuadrados de $\mathrm{ZnO}$ y de $\mathrm{Al}: \mathrm{ZnO}$ fueron impresos sobre los sustratos de silicio tipo- $p$ en un área de $5 \times 5 \mathrm{~mm}^{2}$. Operando en el régimen de goteo-sobre-demanda (DoD), tanto el cartucho como la placa de la impresora fueron calentados a una temperatura de $\sim 30^{\circ} \mathrm{C}$. Además, se configuró una altura entre el inyector y la superficie del sustrato igual a $1 \mathrm{~mm}$, pero es importante estudiar la influencia en la variación de este parámetro. A pesar de que es posible incrementar el espesor de la capa impresa apilando patrones, en este caso sólo se imprimió una vez cada patrón para analizar las diferencias que se producen en el espesor sólo por la variación del espaciamiento entre gotas (distancia del centro de una gota al centro de otra en dirección vertical u horizontal).

Se ha demostrado que los ciclos de limpieza permiten eliminar la obstrucción por burbujas de aire, pero este mecanismo tiende a presentarse nuevamente debido a que las nPs adheridas a las paredes del inyector no son removidas por estos procesos de limpieza (Li et al., 2019). Aunque el cabezal de los cartuchos utilizados tiene 16 inyectores, se eligió sólo un inyector que permitiera realizar un proceso de impresión completo de forma continua, uniforme, repetible y sin requerir ciclos de limpieza para el cabezal del cartucho durante la impresión, esto para minimizar la probabilidad de obstrucción de los inyectores debida a diferentes mecanismos que pudieran comprometer la uniformidad del patrón, su morfología y la homogeneidad del espesor (Dressaire y Sauret, 2017). Cabe señalar que el cartucho cuya capacidad de expulsar un volumen de $1 \mathrm{pL}$ tiene inyectores con un $a$ de $\sim 9 \mu \mathrm{m}$ y que el valor de la $v$ para cada tinta fue extraído usando del visualizador de gotas de la impresora DIMATIX, la cual cuenta con una cámara estroboscópica para capturar una imagen de la distancia de caída de una gota, desde que ésta es expulsada de la boquilla del inyector hasta un tiempo determinado. Configurando un espaciamiento entre gotas (DS) de 15 a $40 \mu \mathrm{m}$, se alcanzan diferentes resoluciones de los patrones de $\mathrm{nPs}-\mathrm{ZnO}$ y de $\mathrm{nPs}-\mathrm{Al}: \mathrm{ZnO}$, que fueron exitosamente impresos para cada DS seleccionado.

Después del proceso de impresión, los patrones impresos fueron tratados térmicamente a $90 \pm 1{ }^{\circ} \mathrm{C}$ durante $10 \mathrm{~min}$ para sinterizar la tinta y evaporar el mayor volumen del solvente. El recocido fue aplicado en una atmósfera de nitrógeno mediante un horno convencional de convección (OV-8A Stabli-Therm).

\subsection{Caracterización de los patrones impresos.}

Finalmente, el área de los patrones impresos de nPs-ZnO y de nPs-Al: $\mathrm{ZnO}$ fue medida usando un microscopio óptico compuesto (VE-146) y una retícula ocular milimétrica. Para los diferentes DS, el espesor fue medido mediante un elipsómetro de ángulo variable (L116S300) a una longitud de onda $(\lambda)$ de $632 \mathrm{~nm}$ y de 824 $\mathrm{nm}$. La microscopía por fuerza atómica (AFM) de los patrones impresos se realizó en el modo de semi-contacto a una frecuencia de barrido entre 0.5 y $1 \mathrm{~Hz}$ en un visualizador molecular (Pico+ SPM II). Las micrografías fueron obtenidas en una atmósfera al aire, utilizando puntas de prueba convencionales de silicio con una constante de elasticidad entre 1 y $5 \mathrm{nN} / \mathrm{m}$ y una frecuencia de resonancia de $75 \mathrm{kHz}$.

\section{Análisis y discusión de resultados.}

En diferentes estudios se han implementado patrones impresos de materiales MOS en la estructura de algún dispositivo semiconductor de película delgada, como la capa activa en un TFT (Chung et al., 2008), en fotodetectores ultravioleta de alta sensibilidad (Nahlik et al., 2019) o como capa de transporte de electrones en celdas solares poliméricas invertidas (Sacramento et al., 2020). Todos estos coinciden en la importancia de caracterizar a detalle y comprender las condiciones que producen diferentes morfologías, espesores y uniformidad de los patrones impresos para optimizarlos en el desempeño de tales dispositivos. Por estos motivos, se analizan los resultados sobre la rugosidad de la superficie, el espesor y la uniformidad del área obtenidos de los patrones impresos por inyección piezoeléctrica de tintas comerciales con $\mathrm{ZnO}$ y $\mathrm{Al}: \mathrm{ZnO}$ en forma de nPs dispersadas. Esto se realizó a través del control en la preparación previa de las tintas y el equipo utilizado; además, de la configuración pertinente de la impresora, tal como la forma de onda del pulso de voltaje aplicado al cabezal de impresión o la variación del DS

\subsection{Imprimibilidad de las tintas basadas en óxido de zinc.}

La Tabla 1 resume las propiedades reológicas y los valores obtenidos de los números adimensionales para las tintas usadas.

Los límites trazados con las líneas punteadas en el mapa de la Figura 1(a) se refieren a los criterios físicos propuestos por (Derby y Reis, 2003). Como se observa en la Figura 1(a), las tintas usadas se posicionan en la región de imprimibilidad, lo cual indica que sus propiedades reológicas cumplen con los criterios mencionados para asegurar que la fuerza inercial puede superar tanto la viscosidad como la tensión superficial del fluido en la boquilla del inyector, y también que la magnitud de esta fuerza previene la formación de gotas satélite y salpicaduras por el impacto con la superficie del sustrato. Además, se observa que los números adimensionales de las tintas de $\mathrm{ZnO}$ y $\mathrm{Al}: \mathrm{ZnO}$ las ubican cerca del límite donde $Z=1$, por lo que destaca la importancia de la viscosidad para la imprimibilidad de un material procesado en solución.

En el esquema en la Figura 1(b), los límites marcados por las líneas punteadas corresponden a los criterios sugeridos por (Schiaffino y Sonin, 1997), los cuales acotan las regiones que representan los procesos físicos que influyen en el comportamiento de una gota eyectada al impactar con la superficie del sustrato donde ha sido depositada. Como se observa en la Figura 1(b), las

Tabla 1: Propiedades reológicas de las tintas comerciales de $\mathrm{ZnO}$ y $\mathrm{Al}: \mathrm{ZnO}$, las cuales fueron usadas en el proceso de impresión, y números adimensionales de Reynolds, Weber, Ohnersorge y $Z$ determinados a partir de éstas.

\begin{tabular}{|c|c|c|c|}
\hline Material & $\begin{array}{c}\mathbf{Z n O} \\
(v \sim 16 \mathrm{~m} / \mathrm{s})\end{array}$ & $\begin{array}{c}\mathbf{Z n O} \\
(v \sim 10 \mathrm{~m} / \mathrm{s})\end{array}$ & $\begin{array}{c}\mathbf{A l}: \mathbf{Z n O} \\
(v \sim 16 \mathrm{~m} / \mathrm{s})\end{array}$ \\
\hline$\rho\left(\mathrm{kg} / \mathrm{m}^{3}\right)$ & \multicolumn{2}{|c|}{940} & 900 \\
\hline$\eta(\mathrm{mPa} \cdot \mathrm{s})$ & \multicolumn{2}{|c|}{$11 \pm 3$} & $12 \pm 4$ \\
\hline$\gamma\left(\mathrm{mJ} / \mathrm{m}^{2}\right)$ & \multicolumn{2}{|c|}{$29 \pm 5$} & 49 \\
\hline$R e$ & 12.3 & 7.7 & 10.8 \\
\hline$W e$ & 74.7 & 29.2 & 42.7 \\
\hline Oh & 0.7 & 0.7 & 0.6 \\
\hline$Z$ & 1.4 & 1.4 & 1.7 \\
\hline
\end{tabular}


tintas usadas se ubican en la región superior/izquierda, esto indica que la gota de tinta se propaga sobre la superficie debido a su velocidad de impacto y que la fuerza que se opone a su dispersión se debe sólo a su misma inercia. Conforme se reduce la energía cinética, la viscosidad debería tener un efecto predominante, pero en los casos analizados, dicha propiedad tiene una mínima influencia en la dispersión de las gotas sobre el sustrato, acorde a la posición en que éstas se sitúan dentro del esquema de la Figura 1(b).

Los resultados de imprimibilidad e interacción con el sustrato muestran que tanto la tinta de $\mathrm{ZnO}$ como la de $\mathrm{Al}: \mathrm{ZnO}$ son viables para su uso en un proceso de impresión por inyección de tinta debido a que sus propiedades reológicas cumplen con algunos de los criterios sugeridos para equipos de DoD (Derby y Reis, 2003), (Schiaffino y Sonin, 1997).

\subsection{Configuración del proceso de impresión.}

La formación de gotas de tinta y su expulsión desde la boquilla del inyector se realiza mediante una señal eléctrica o forma de onda (WF) que estimula la membrana piezoeléctrica en el cabezal de los cartuchos usados. De esta forma, las propiedades reológicas son determinantes en el desempeño de una tinta utilizada en una impresora de DoD, pero la WF también influye directamente en el

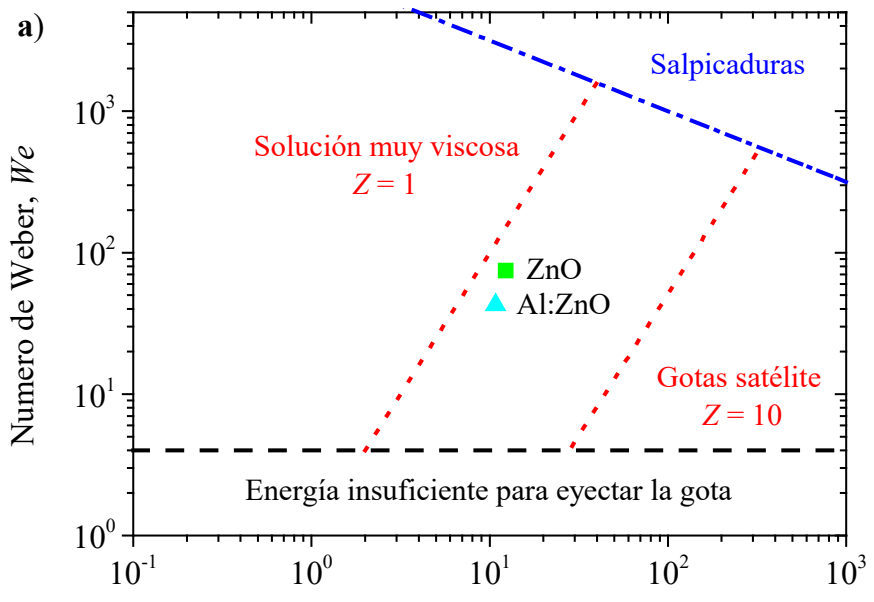

Numero de Reynolds, Re

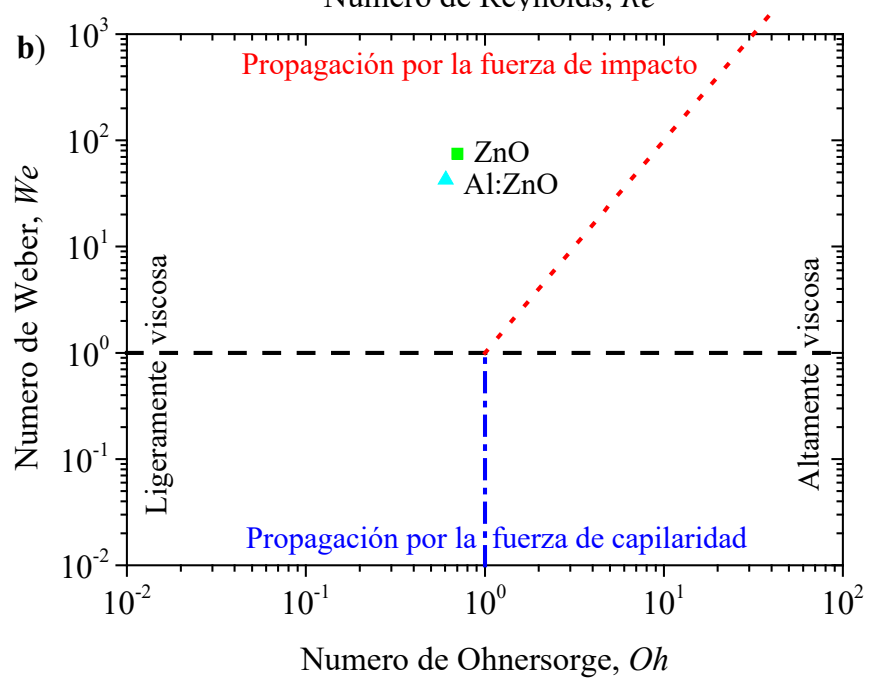

Figura 1. a) Mapa de imprimibilidad con la posición de las tintas de ZnO y Al:ZnO, representando el mecanismo de formación y expulsión de gotas con la impresora DoD. b) Esquema que representa los tipos de interacción de una gota que impacta sobre un sólido, donde la posición de estas tintas exhibe una propagación dominada por la fuerza de impacto.
Tabla 2: Parámetros de configuración para las formas de onda diseñadas como en la Figura 2 y usadas en el proceso de impresión de la tinta comercial de $\mathrm{ZnO}$ y $\mathrm{Al}: \mathrm{ZnO}$.

\begin{tabular}{|c|c|c|c|c|c|}
\hline \multicolumn{2}{|c|}{ Material } & \multicolumn{3}{|c|}{$\mathrm{ZnO}$} & Al:ZnO \\
\hline \multicolumn{2}{|c|}{ Amplitud pico $(V)$} & $\sim 37$ & $\sim 17$ & $\sim \sim 13$ & $\sim 18$ \\
\hline \multicolumn{2}{|c|}{ Duración $(\mu s)$} & $\sim 9$ & \multicolumn{2}{|c|}{$\sim 11$} & $\sim 11$ \\
\hline Velocidad & Max & +1.4 & \multicolumn{2}{|c|}{+0.74} & +0.74 \\
\hline de cambio & Min & -1.5 & \multicolumn{2}{|c|}{-2.0} & -2.0 \\
\hline \multicolumn{2}{|c|}{$\begin{array}{l}\text { Frecuencia de } \\
\text { inyección (kHz) }\end{array}$} & \multicolumn{3}{|c|}{5} & 5 \\
\hline \multicolumn{2}{|c|}{$\begin{array}{c}\text { Velocidad de caída } \\
\qquad(\mathrm{m} / \mathrm{s})\end{array}$} & $\sim 16$ & $\sim 16$ & $\sim 10$ & $\sim 16$ \\
\hline \multicolumn{2}{|c|}{ Inyección de tinta } & $\begin{array}{l}\text { Sin gotas } \\
\text { satélite }\end{array}$ & \multicolumn{2}{|c|}{$\begin{array}{l}\text { Con gotas } \\
\text { satélite }\end{array}$} & $\begin{array}{l}\text { Con gotas } \\
\text { satélite }\end{array}$ \\
\hline
\end{tabular}

mecanismo de formación y expulsión de gotas, y en su velocidad de caída, donde su campo de acción estará limitado por las propias prestaciones del equipo DoD.

Considerando los resultados obtenidos para la tinta de $\mathrm{ZnO}$ sobre la imprimibilidad y su interacción al impactar con la superficie del sustrato, primero se configuró una WF como se muestra en la Figura 2 con la línea sólida. Adicionalmente, la línea punteada describe otra de las WF utilizadas, la cual fue diseñada con una configuración distinta, principalmente en la etapa de formación de las gotas, aunque ambas WF resultan en una $v$ de $\sim 16 \mathrm{~m} / \mathrm{s}$. La Tabla 2 resume los parámetros generales para configurar las WF diseñadas como se muestra en la Figura 2, y que fueron empleadas para la formación y expulsión de las gotas de tintas comerciales de $\mathrm{ZnO}$ y $\mathrm{Al}: \mathrm{ZnO}$.

Utilizando el visualizador de gotas del equipo DIMATIX, se capturó una serie de imágenes individuales de las gotas que producen las WF de la Figura 2, aumentando el tiempo de retardo en que la cámara estroboscópica captura la imagen desde que la gota es eyectada en la boquilla del inyector hasta que ésta casi sale del campo de visión, en un rango entre $6 \mu \mathrm{s}$ y $62 \mu \mathrm{s}$.

La Figura 3(a) muestra la expulsión de tinta de $\mathrm{ZnO}$ en forma de gotas esféricas ( $\sin$ gotas satélite), lo que coincide con los criterios sobre la imprimibilidad de una tinta por medio de una impresora de DoD. Este resultado fue obtenido al aplicar la WF representada en el esquema de la Figura 2 con la línea sólida.

Al configurar una WF como la línea punteada en la Figura 2, se obtiene una expulsión de gotas como se observa en la secuencia de imágenes de la Figura 3(b), donde es clara la formación de una

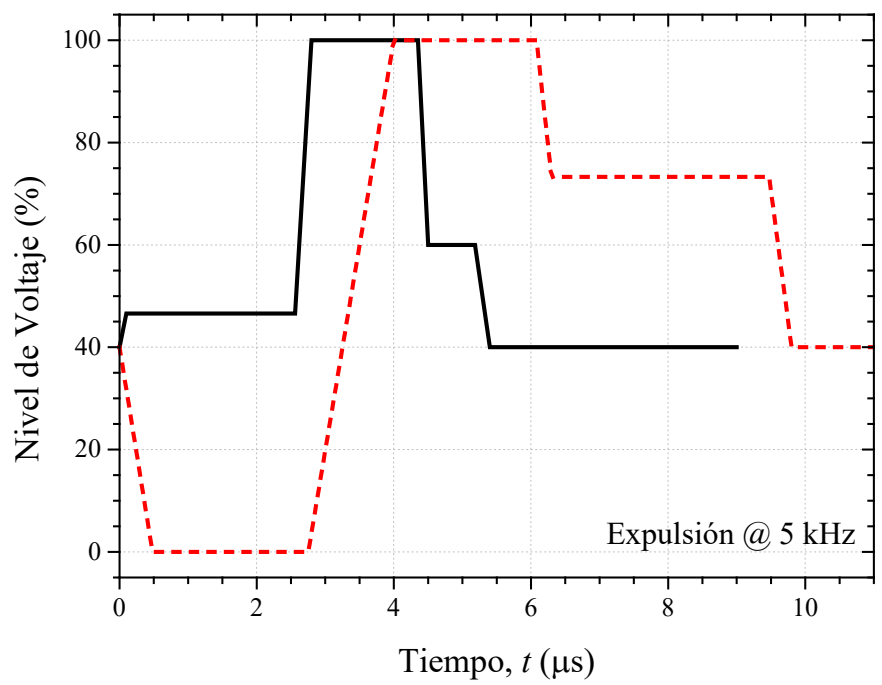

Figura 2. Representación esquemática de las WFs usadas para generar y eyectar una gota a través del inyector: sin gotas satélite (línea sólida) y con gotas satélite (línea punteada). 


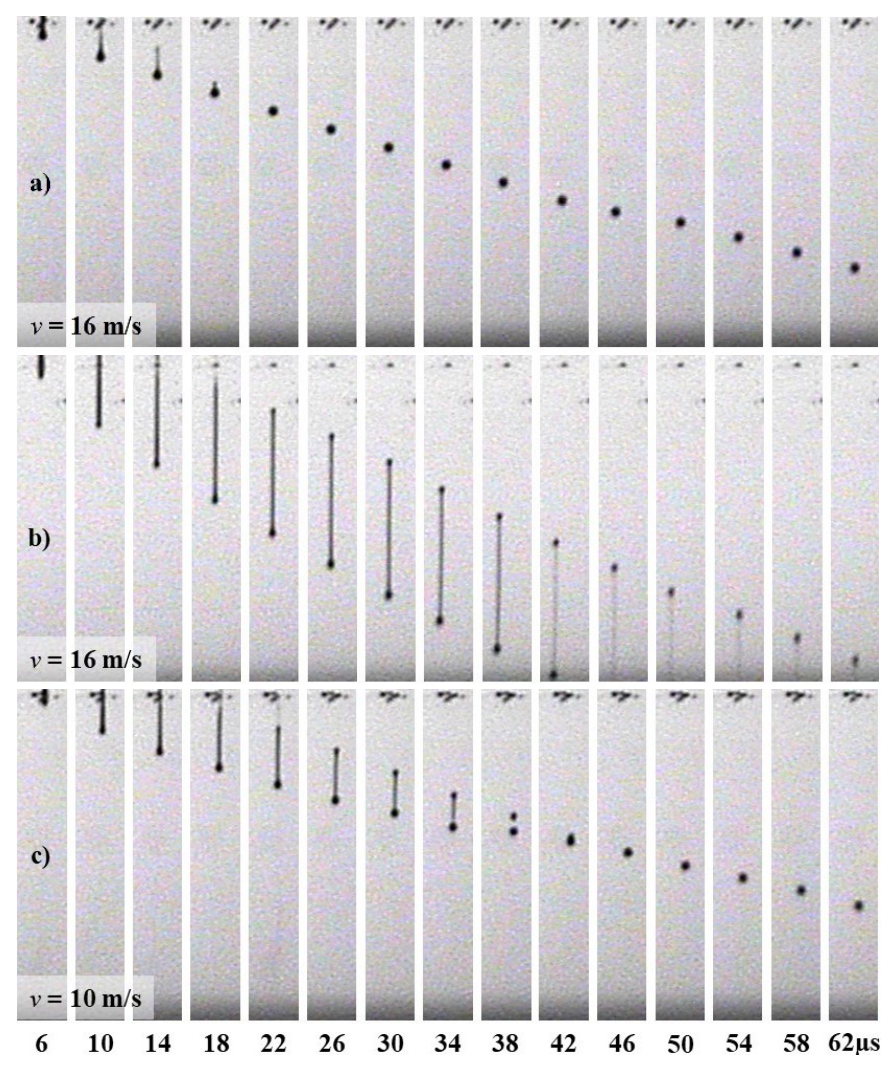

Figura 3. Imágenes de la expulsión de gotas de la tinta de ZnO, usando las WF mostradas en la Figura 2: a) sin gotas satélite; b) con gotas satélite; c) retracción de gotas satélite.

gota principal (parte inferior) con la eyección de una columna o filamento del fluido, que se adelgaza con el incremento de su trayectoria de caída hasta la formación de una gota satélite (parte superior). Esto demuestra que la presencia de gotas satélite puede ocurrir, aunque la WF usada también produzca una $v$ de $\sim 16 \mathrm{~m} / \mathrm{s}$, los números adimensionales de $\operatorname{Re}(12.3)$ y $W e$ (74.7) sean iguales y la tinta esté ubicada en la misma posición dentro del mapa de imprimibilidad en la Figura 1(a).

Asimismo, se usó la misma WF diseñada como la línea punteada en la Figura 2, pero configurando una amplitud pico $\left(\mathrm{A}_{\mathrm{P}}\right) \mathrm{de}$ $12.5 \mathrm{~V}$, que resultó en una $v$ de $\sim 10 \mathrm{~m} / \mathrm{s}$, así como valores de $R e=7.7, W e=29.17, O h=0.7$ y $Z=1.42$. El uso de estos parámetros derivó en una eyección de gotas como lo exhibe la Figura 3(c), donde se distingue la reducción en la altura de la columna del fluido que se expulsa con la gota principal. Conforme aumenta su trayectoria de caída, el filamento se contrae y se observa la formación de una gota satélite hasta que, después de $42 \mu$ s de caída, ambos elementos se retraen hacia una sola gota. Esto coincide con el análisis realizado por (Notz y Basaran, 2004), que consistió en el modelado de la estabilidad del filamento de un fluido que se forma al ser expulsado a través de un inyector, reportando que para las tintas estudiadas con un valor de $Z<10$, dicho filamento presentó la retracción hacia una esfera; mientras que, para valores mayores de $Z$ se mostró la disminución en el grosor del filamento y la respectiva generación de gotas satélites. Además, comparando los resultados de la formación y expulsión de gotas de tinta presentados en la Figura 3(b) y 3(c), se observa una reducción en la velocidad de la gota eyectada al disminuir la $A_{P}$ del voltaje que es aplicado a través de la WF. Este efecto coincide con el estudio realizado por (Dong et al., 2006), que a partir de tres fluidos reportaron la formación de gotas mediante un equipo de impresión DoD. Los tres casos resultaron en un numero adimensional $Z$ de $4.4,8.9$ y 6.2 , por lo que se ubicaban en la región de imprimibilidad dentro del mapa respectivo; además, se demostró que tanto la longitud de la columna del líquido eyectado como la magnitud de su $v$ incrementaban al aumentar la $\mathrm{A}_{P}$ del voltaje aplicado.

$\mathrm{Al}$ emplear la técnica de impresión por inyección piezoeléctrica tanto la imprimibilidad de una tinta como la configuración de la WF y de su $A_{P}$ permiten controlar el desempeño del proceso, eliminando las gotas satélite, esto no previene la obstrucción de las boquillas de los inyectores del cabezal, por lo que es necesario incluir ciclos de limpieza en el proceso de impresión para reducir esta probabilidad, lo cual compromete la uniformidad del patrón impreso y, por lo tanto, el control de su morfología y del espesor de la capa. Con esta consideración, sólo la WF diseñada como la línea punteada en la Figura 2, que produce una expulsión de gotas de tinta de $\mathrm{ZnO}$ con un filamento y una gota satélite, permitió la eyección continua, uniforme y repetible, manteniendo las boquillas de los inyectores sin obstrucción, por lo que se eligieron estos parámetros de configuración para la impresión de patrones de $\mathrm{ZnO}$ y se prescindió de los ciclos de limpieza durante el proceso.

Conforme los resultados obtenidos para la tinta de $\mathrm{Al}: \mathrm{ZnO}$, relacionados a su imprimibilidad y su interacción al impactar con el sustrato, y dado que esta tinta tiene propiedades reológicas similares a aquellas de la tinta de $\mathrm{ZnO}$ (Tabla 1), para imprimir patrones de $\mathrm{Al}: \mathrm{ZnO}$ se configuró la misma WF mostrada en la Figura 2 con la línea punteada. De este modo, la señal eléctrica que estimula la membrana piezoeléctrica fue diseñada con los parámetros que se enlistan en la Tabla 2 , estos también produjeron una $v$ de la gota eyectada de $\sim 16 \mathrm{~m} / \mathrm{s}$. Con el visualizador de gotas se realizó una serie de capturas de las gotas de $\mathrm{Al}: \mathrm{ZnO}$ generadas por la WF mostrada con la línea punteada en la Figura 2, aumentando el tiempo de retardo de la cámara desde $6 \mu$ s hasta $62 \mu$ s. Como se exhibe en la Figura 4, para la tinta de $\mathrm{Al}: \mathrm{ZnO}$ se obtiene una eyección compuesta de una gota principal y una columna del fluido, donde esta última se prolonga y adelgaza hasta que ambos componentes se separan de la boquilla del inyector en $22 \mu$ s. Después, esta columna continúa adelgazándose y se contrae conforme cae la gota, hasta que se forma claramente una gota satélite y, después de $54 \mu$ s de caída, se observa que sólo ésta sigue a la gota principal. Aunque la WF usada produjo una expulsión de gotas de tinta de Al:ZnO como en la Figura 4, los parámetros de configuración empleados permitieron un proceso continuo, uniforme, repetible y manteniendo el borde de los inyectores libre de oclusión. A pesar de que en ambas tintas se genera una misma $v$, al comparar los resultados obtenidos con la tinta de $\mathrm{ZnO}$, las gotas eyectadas de $\mathrm{Al}: \mathrm{ZnO}$ presentaron un filamento del fluido que se contrae, esto se debe al ligero incremento en la viscosidad de la tinta de $\mathrm{Al}: \mathrm{ZnO}$.

\subsection{Control de la morfología.}

Por medio del software de control de la impresora se configuró el

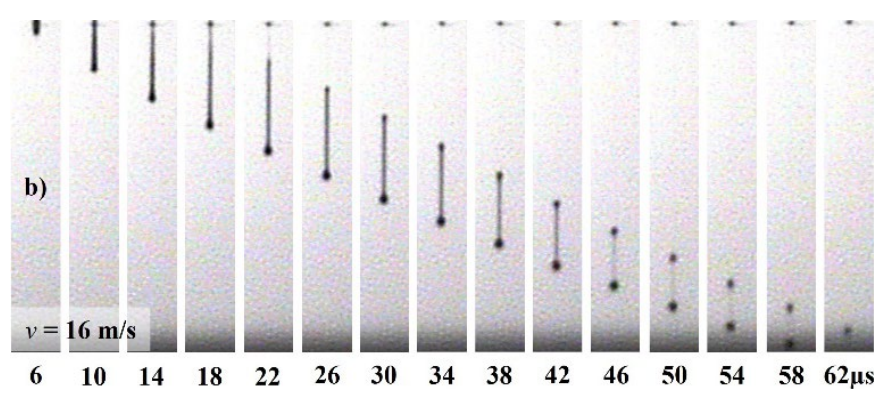

Figura 4. Secuencia de imágenes de la expulsión de gotas de la tinta de Al:ZnO, considerando la WF como la línea punteada de la Figura 2, pero $\sim 18 \mathrm{~V}$ de Ap. Trayectoria de caída en intervalos de retardo de la cámara estroboscópica de $4 \mu \mathrm{s}$. 
Espaciamiento entre gotas $(\mu \mathrm{m}) /$ Ángulo del cartucho $\left({ }^{\circ}\right)$

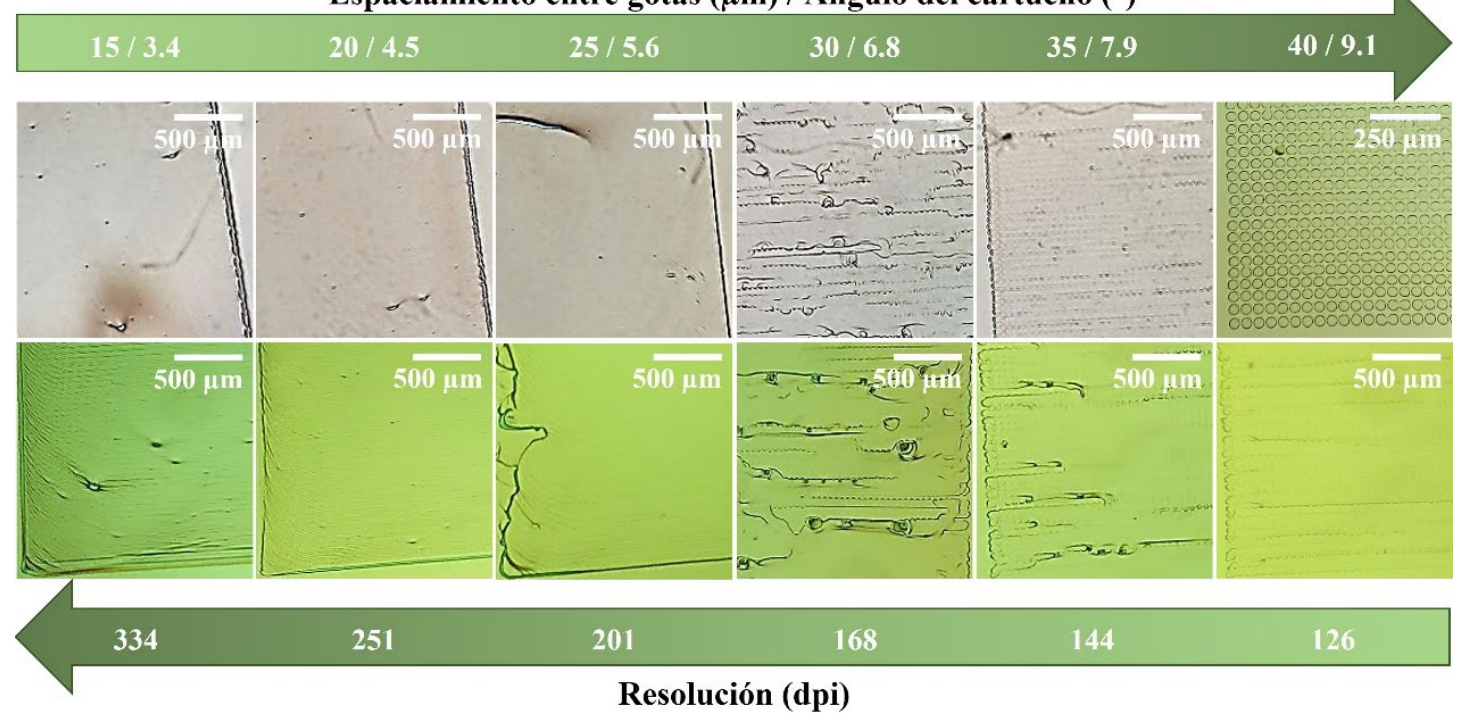

Figura 5. Micrografías ópticas mostrando la evolución del patrón impreso, al variar el DS de 15 $\mu \mathrm{m}$ a $40 \mu \mathrm{m}$, lo cual requirió el cambio en el ángulo de montaje del cartucho y aumentó la resolución lineal del patrón cuadrado con la tinta de $\mathrm{ZnO}$ (superior) y la tinta de $\mathrm{Al}: \mathrm{ZnO}$ (inferior).

DS, el cual provee la resolución en el eje horizontal y el ángulo del cartucho hace lo propio en el eje vertical (Fujifilm Dimatix Inc., 2016). Esto es muy importante ya que la variación del DS y, por lo tanto, de la resolución originan diferencias en la morfología del patrón impreso, aunque existe un compromiso con el espesor de la capa y la uniformidad del área resultante.

Los patrones impresos y mostrados en las micrografías ópticas (OMs) de la Figura 5(superior) fueron obtenidos mediante el uso de los parámetros de impresión y condiciones de tratamiento térmico para la tinta de $\mathrm{ZnO}$ antes mencionados. Con una eyección de gotas continua, uniforme y repetible, se observa que la morfología del patrón impreso depende fuertemente del DS seleccionado, donde se puede producir desde una impresión formada por gotas individuales (DS $\geq 40 \mu \mathrm{m}$ ) hasta una superficie con homogeneidad visible al reducir el $\mathrm{DS} \leq 25 \mu \mathrm{m}$.

En el patrón impreso de $\mathrm{ZnO}$ con un $\mathrm{DS}=40 \mu \mathrm{m}$ es notable que los parámetros usados permitieron generar una impresión controlada en un arreglo con gotas individuales y alineadas en ambos grados de libertad del proceso. Esto también permite suponer que las gotas depositadas tienen un diámetro de $\sim 40 \mu \mathrm{m}$, que coincide con lo reportado por el fabricante del equipo de impresión (Fujifilm Dimatix Inc., 2016). Aunque al reducir el DS a $35 \mu \mathrm{m}$ se produjo un traslape entre gotas, éste no fue suficiente para obtener la completa coalescencia entre las gotas en dirección vertical, lo cual también se presentó para un $\mathrm{DS}=30 \mu \mathrm{m}$, e incluso, con esta resolución se obtuvo un patrón de menor homogeneidad visible. A partir de un DS de $25 \mu \mathrm{m}$ se observa la incorporación completa de las gotas en ambos ejes, lo cual mejoró la morfología en el área impresa y se obtuvieron películas uniformes. Al respecto, (Samos et al., 2019) reportaron que el ángulo de contacto entre la gota y la superficie del sustrato puede ser un parámetro importante para fomentar la interacción y coalescencia de las gotas impresas; es decir, conforme aumenta el ángulo de contacto las gotas depositadas no logran propagarse sobre el sustrato para integrarse totalmente entre ellas, por lo que se requiere incrementar la resolución. Mientras que al reducir dicho ángulo se alcanza una superficie homogénea, configurando una menor resolución.

Para el análisis de la morfología de los patrones impresos con la tinta de $\mathrm{ZnO}$ se exhiben algunas de las imágenes topográficas obtenidas por AFM en la Figura 6(a) y 6(b), sobre un área de escaneo de $30 \mu \mathrm{m}$ por lado en la región central del patrón con un DS de $20 \mu \mathrm{m}$ y de $30 \mu \mathrm{m}$. A partir de estas mediciones, se observó un aumento en la rugosidad de los patrones de $\mathrm{ZnO}$ conforme incrementó el DS; de forma que al superponer gotas se produjo una rugosidad cuadrática media (RMS) con un mínimo de $1.4 \mathrm{~nm}$ y un máximo de $2.6 \mathrm{~nm}$, mientras que la altura pico-a-valle (PTV) fue inferior a $60 \mathrm{~nm}$ cuando el DS se configuró entre $15 \mu \mathrm{m}$ y $35 \mu \mathrm{m}$. En el caso de un $\mathrm{DS}=40 \mu \mathrm{m}$, se presentó un aumento de la rugosidad con un valor $\mathrm{RMS}=8.12 \mathrm{~nm}$ y una altura $\mathrm{PVT}=177.74 \mathrm{~nm}$, la cual se atribuye a la impresión de gotas individuales y a una ligera acumulación de las nPs de $\mathrm{ZnO}$ hacia la periferia de la gota por el efecto conocido como anillo de café (Mampallil y Eral, 2018). Los patrones impresos y mostrados en las OMs de la Figura 5(inferior) fueron obtenidos mediante los parámetros de impresión y
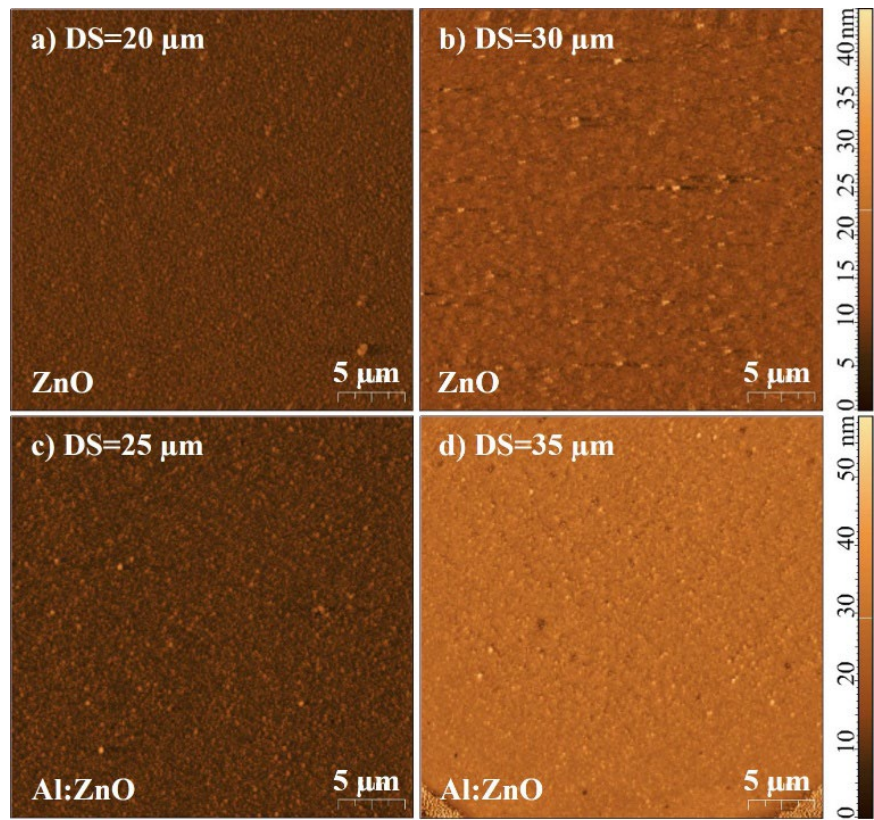

Figura 6. Imágenes de AFM en 2D usando el modo de semicontacto sobre un área de escaneo de $30 \times 30 \mu \mathrm{m}^{2}$ al centro del patrón, los cuales fueron impresos con un DS de a) $20 \mu \mathrm{m}$ y b) $30 \mu \mathrm{m}$, para la tinta de $\mathrm{ZnO}$, y con un DS de c) $25 \mu \mathrm{m}$ y d) $35 \mu \mathrm{m}$, para la tinta de Al:ZnO. 
condiciones de tratamiento térmico previamente indicados para la tinta de Al:ZnO. Después de asegurar que la eyección de gotas es continua, uniforme y repetible, se observó que la morfología de los patrones impresos de $\mathrm{Al}: \mathrm{ZnO}$ también depende del DS configurado. Así, se imprimieron gotas consecutivas e individuales al disponer un DS de $50 \mu \mathrm{m}$ (OMs no mostrada en la Figura 5), obteniéndose superficies homogéneas y densas al reducir el DS por debajo de $30 \mu \mathrm{m}$. Similar a la tinta de $\mathrm{ZnO}$, las condiciones usadas con el patrón impreso de DS $=50 \mu \mathrm{m}$ permitieron imprimir controladamente una matriz de gotas alineadas en el eje vertical y horizontal, lo cual sugiere que las gotas impresas tienen un diámetro de $\sim 50 \mu \mathrm{m}$. Al comparar el resultado de la tinta de Al:ZnO con aquel de la tinta de $\mathrm{ZnO}$, la diferencia en el diámetro de la gota impresa es atribuida a una mayor tensión superficial de la tinta de $\mathrm{Al}: \mathrm{ZnO}$ (véase Tabla 1), la cual influye en la propagación de la gota al impactar sobre la superficie del sustrato, como también se mostró en el esquema de la Figura 1(b).

Como en el caso del $\mathrm{ZnO}$, sólo al aumentar la resolución de impresión mediante un DS $=25 \mu \mathrm{m}$ se completó la integración de las gotas en ambos grados de libertad del proceso, lo que permitió producir la morfología en el área impresa y la uniformidad en las películas de $\mathrm{Al}: \mathrm{ZnO}$ presentadas en la Figura 5(inferior). Además, las mediciones realizadas por AFM exhibieron la morfología de los patrones impresos con la tinta de $\mathrm{Al}: \mathrm{ZnO}$, la cual es mostrada con algunas de las imágenes topográficas obtenidas sobre un área de escaneo de $30 \mu \mathrm{m}$ por lado en la región central de los patrones con un DS de $20 \mu \mathrm{m}$ y $30 \mu \mathrm{m}$ en las Figuras 6(c) y 6(d), respectivamente. De igual forma, se notó un incremento en la rugosidad de los patrones de $\mathrm{Al}: \mathrm{ZnO}$ acorde al aumento en la resolución, donde el traslape entre gotas generó una rugosidad RMS con un mínimo de $2.7 \mathrm{~nm}$ y un máximo de $8.6 \mathrm{~nm}$, mientras que la altura PTV presentó un mínimo de $44 \mathrm{~nm}$ y un máximo de $80 \mathrm{~nm}$, al configurar el DS entre $25 \mu \mathrm{m}$ y $40 \mu \mathrm{m}$, respectivamente.

\subsection{Control del espesor.}

Aplicando la técnica de elipsometría para medir el espesor del patrón impreso, cada uno fue medido en tres puntos diferentes; es decir, sobre la región central y en zonas cercanas a ambos extremos, ya sea izquierda y derecha o superior e inferior. En la Figura 7 se muestra el espesor promedio medido con respecto a la varia-

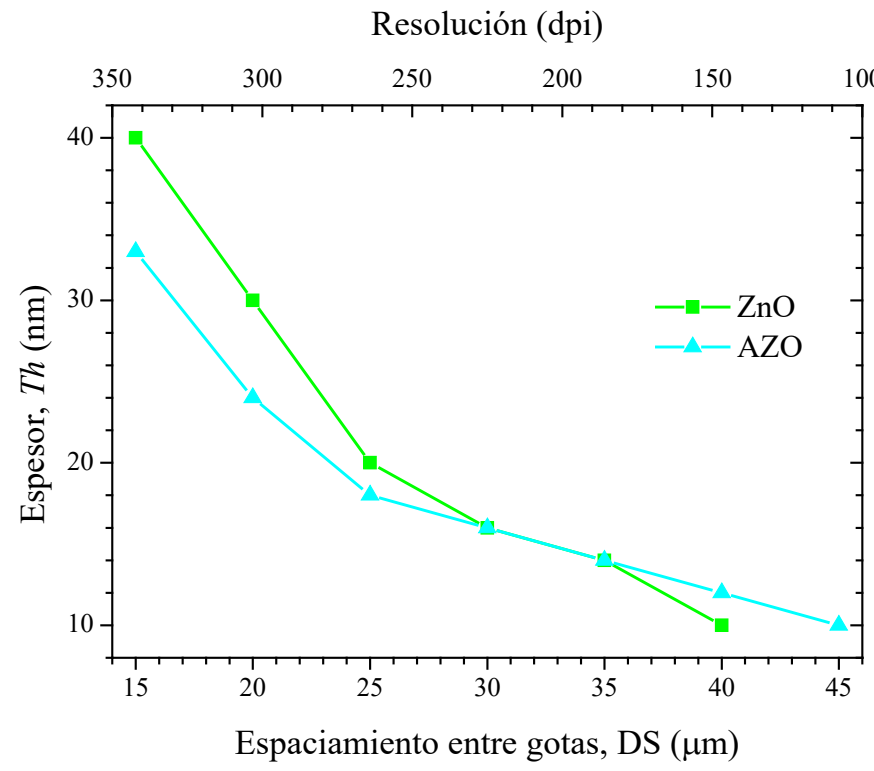

Figura 7. Espesor promedio medido en los patrones impresos con un diferente DS, desde $15 \mu \mathrm{m}$ hasta $45 \mu \mathrm{m}$.
Tabla 3: Valores del índice de refracción $(n)$, del coeficiente de extinción $(k)$ y de referencia utilizados para la determinación del espesor del patrón impreso, a diferente longitud de onda $(\lambda)$.

\begin{tabular}{cccc}
\hline Material & & ZnO & Al:ZnO \\
\hline \multirow{2}{*}{$\lambda=632.8 \mathrm{~nm}$} & $n$ & $1.63 \pm 0.05$ & $1.73 \pm 0.07$ \\
& $k$ & $0.16 \pm 0.1$ & $0.09 \pm 0.04$ \\
$\lambda=824.3 \mathrm{~nm}$ & $n$ & $1.62 \pm 0.1$ & $1.62 \pm 0.07$ \\
& $k$ & $0.55 \pm 0.3$ & $0.03 \pm 0.02$ \\
Referencia & $n$ & $1.63^{*}$ & $1.8^{* *}$ \\
& $k$ & $0.02^{1^{*}}$ & $0.003^{* *}$
\end{tabular}

*(Treharne et al., 2011). **(Stelling et al., 2017).

ción en la resolución del patrón obtenido entre 334 dpi y 112 dpi, por lo tanto, acorde al DS configurado en el proceso de impresión para las tintas de $\mathrm{ZnO}$ y $\mathrm{Al}: \mathrm{ZnO}$.

En general, el espesor de los patrones impresos se reduce con respecto a la disminución de su resolución o acorde al aumento en el DS sin importar el material que haya sido depositado, como se puede observar de la Figura 7. Además, en la variación del espesor se exhibe un comportamiento con dos pendientes diferentes, donde la mayor de éstas está relacionada con la incorporación completa de las gotas en ambos ejes de impresión y, por lo tanto, con la obtención de superficies visiblemente más homogéneas. Mientras que la menor pendiente parece estar asociada con una saturación hacia el mínimo espesor que es posible imprimir, debido a un menor traslape entre gotas adyacentes y al tamaño de las $\mathrm{nPs}$ de cada material procesado en solución.

En el caso del $\mathrm{ZnO}$, el espesor del patrón impreso aumenta ligeramente desde $10 \mathrm{~nm}$ hasta $16 \mathrm{~nm}$ en un rango de $25 \mu \mathrm{m}<\mathrm{DS}$ $\leq 40 \mu \mathrm{m}$, donde el grosor corresponde al rango del tamaño promedio de las nPs, reportado por el fabricante (Sigma-Aldrich, 2021). Posteriormente, se presenta un incremento de aproximadamente $20 \mathrm{~nm}$ cuando se dispone un rango entre $15 \mu \mathrm{m} \leq \mathrm{DS} \leq 25 \mu \mathrm{m}$.

Con el uso de la tinta de $\mathrm{Al}: \mathrm{ZnO}$, se observó un comportamiento similar a la variación del espesor en los patrones impresos de $\mathrm{ZnO}$, donde un DS en el rango entre $25 \mu \mathrm{m}<\mathrm{DS} \leq 45 \mu \mathrm{m}$ produjo un grosor de $10 \mathrm{~nm}$ hasta $18 \mathrm{~nm}$, mientras que un aumento hasta un valor máximo de $33 \mathrm{~nm}$ fue obtenido con un DS de 15 $\mathrm{nm}$. Aunque el tamaño promedio de las nanopartículas de $\mathrm{ZnO}$ es equivalente a las de Al:ZnO (Sigma-Aldrich, 2021), es notable que los espesores producidos son ligeramente menores en el último caso, lo cual confirma que un aumento de la tensión superficial de $\sim 20 \mathrm{~mJ} / \mathrm{m}^{2}$ influye en la interacción de las gotas expulsadas de la tinta de $\mathrm{Al}: \mathrm{ZnO}$ al impactar con el sustrato, extendiendo el fluido sobre la superficie, que resulta en un mayor diámetro de la gota impresa y en una pendiente decreciente del espesor más suave, al comparar con la tendencia observada de la tinta de $\mathrm{ZnO}$.

En la Tabla 3 se resumen los valores del índice de refracción $(n)$ y del coeficiente de extinción $(k)$ utilizados para la determinación del espesor de los patrones impresos con $\mathrm{ZnO}$ y $\mathrm{Al}: \mathrm{ZnO}$. Como se puede observar, los valores considerados son bastante cercanos a aquellos de referencia que han sido reportados en trabajos de investigación previos, donde las ligeras diferencias se pueden deber a los residuos del solvente que fue usado para dispersar las nPs de ambos materiales (Mampallil y Eral, 2018).

\subsection{Control de la uniformidad del área.}

Un microscopio óptico compuesto con una retina ocular milimétrica fue utilizado para medir el área resultante de los materiales depositados y definidos mediante la técnica de impresión por inyección piezoeléctrica de tinta.

La Tabla 4 resume los valores de las longitudes medidas experimentalmente tanto en el eje horizontal como en el vertical, que 
Tabla 4: Longitudes medidas en ambos ejes de impresión que definen el área del patrón impreso, acorde a la resolución del patrón en una dirección.

\begin{tabular}{cccc}
\hline \multirow{2}{*}{ DS $(\boldsymbol{\mu m})$} & \multirow{2}{*}{ Resolución } & \multicolumn{2}{c}{ Área medida $\mathbf{X} \times \mathbf{Y}\left(\boldsymbol{\mu \mathbf { m } ^ { 2 } )}\right.$} \\
\cline { 3 - 4 } & & $\mathbf{Z n O}$ & $\mathbf{A l}: \mathbf{Z n O}$ \\
\hline 15 & 334 & $5194 \times 5011$ & $5027 \times 5055$ \\
20 & 251 & $4996 \times 5053$ & $5046 \times 5039$ \\
25 & 201 & $4996 \times 4981$ & $5030 \times 5083$ \\
30 & 168 & $5034 \times 5028$ & $5048 \times 5048$ \\
35 & 144 & $5002 \times 5028$ & $5034 \times 4903$ \\
40 & 126 & $5025 \times 5010$ & $4992 \times 5071$ \\
\hline
\end{tabular}

delimitan el área impresa acorde al cuadrado diseñado y a la variación del DS usado, o bien, a su resolución en ambas dimensiones. Si bien el área diseñada fue de $5 \times 5 \mathrm{~mm}^{2}$, se observa que existen ligeras diferencias en el área impresa debido a que para imprimir sobre una determinada longitud se considera el DS en ambas direcciones y no el diámetro de la gota impresa.

Aunque se ha demostrado que las condiciones del proceso y los parámetros de impresión utilizados permiten producir desde patrones impresos formados por una matriz de gotas individuales hasta superficies más homogéneas con una diferente rugosidad y un espesor determinado, los cuales dependen del DS, en el caso de la uniformidad del área impresa que delimita al patrón también influyó la interacción y coalescencia de las gotas adyacentes, cuando éstas son impresas con un traslape de una cierta magnitud. Un claro ejemplo de esta dependencia es el caso del DS $=15 \mu \mathrm{m}$, usado para la impresión de patrones con la tinta de $\mathrm{ZnO}$, donde se obtuvo la diferencia más significativa entre la dimensión diseñada y el valor medido en el patrón impreso, la cual fue de $\sim 194 \mu \mathrm{m}$ sólo en la dirección horizontal. Cabe recordar que, en la secuencia de impresión del equipo, el carro de la impresora que controla el cartucho sólo se desplaza en el eje horizontal, realizando la expulsión de las gotas. Después, el carro regresa a su posición inicial, mientras que la placa de vacío se mueve en dirección vertical para iniciar otra línea de impresión y así sucesivamente hasta cubrir el área previamente diseñada; es decir, se imprime línea por línea de forma horizontal (Fujifilm Dimatix Inc., 2016).

Anteriormente, (Soltman y Subramanian, 2008) propusieron un modelo para describir el comportamiento de una gota que impacta en el borde de una línea humedecida de gotas previamente impresas, la cual se asume de forma cilíndrica y uniforme. Considerando que el volumen de un fluido que está siendo impreso por unidad de longitud dependerá del volumen de la gota expulsada $\left(V_{\text {drop }}\right)$ y del DS; además, suponiendo que dichas gotas pueden fluir entre ellas para formar un cilindro de volumen equivalente con el respectivo ángulo de contacto $\left(C A_{E}\right)$ y de radio $R_{C}$, expresando este último valor como una relación con el radio de una gota independiente $\left(R_{0}\right)$ :

$$
\frac{R_{C}}{R_{0}}=\sqrt{\frac{2 \times V_{\text {drop }}}{\pi \times D S \times C A_{E} \times R_{0}{ }^{2}}}
$$

donde el valor del $C A_{E}$ representa un factor del ángulo de contacto para corregir el área de la sección transversal de la línea cilíndrica de gotas, a partir de una sección transversal semicircular ideal con un ángulo de contacto de $90^{\circ}$, que se puede expresar como (Soltman y Subramanian, 2008):

$$
C A_{E}=\frac{2}{\pi}\left(\frac{\theta}{\sin ^{2} \theta}-\cot \theta\right)
$$

donde $\theta$ es el ángulo de contacto entre el borde de la gota impresa y la superficie del sustrato.

En el sistema considerado, (Soltman y Subramanian, 2008) se demostró que una gota de tinta eyectada impactará en su mayoría sobre una línea cilíndrica de gotas previamente impresas y fluirá hacia dicho cilindro, en vez de expandirse sobre la superficie del sustrato, cuando se cumple la condición $\mathrm{DS}<R_{0}$. Esto también resulta en un aumento de las dimensiones del cilindro ya impreso y, por lo tanto, en un incremento del $R_{C}$. Mientras que una condición DS $>R_{0}$ produce diferentes interacciones entre la gota expulsada que impacta tanto a dicha línea cilíndrica como a la superficie del sustrato. Esto genera distintas morfologías de la línea impresa resultante, que puede tener la forma de bordes ondulados, monedas apiladas, abultamientos, o un patrón uniforme, incluso de gotas independientes cuando se configura un DS $\geq 2 \times R_{0}$.

Considerando que el equipo DIMATIX imprime horizontalmente línea por línea, el modelo propuesto por (Soltman y Subramanian, 2008) permite justificar el aumento en una dimensión de los cuadrados impresos de $\mathrm{ZnO}$ cuando se configura un $\mathrm{DS}=15$ $\mu \mathrm{m}$. Esto se debe a que el $R_{0}$ de las gotas impresas de $\mathrm{ZnO}$ es de $\sim 20 \mu \mathrm{m}$ y cada gota que impacta la línea cilíndrica ya impresa, fluye hacia esta línea, aumentando su $R_{C}$. Además, esto sólo ocurre horizontalmente porque la línea que está en proceso de impresión aún está humedecida $\mathrm{y}$, al iniciar la impresión de una nueva línea en otra posición vertical, la anterior ya ha sido expuesta a un proceso térmico y se ha evaporado ligeramente, por la temperatura configurada para el cartucho y la placa de vacío, lo cual no permite la misma interacción en dirección vertical y, por lo tanto, al parecer la tinta sólo fluye y produce dicha expansión en una dirección.

El modelo propuesto por (Soltman y Subramanian, 2008) también podría explicar las morfologías obtenidas en los patrones impresos con las nPs-ZnO, a través de la relación descrita en (1), y de su dependencia con el ángulo de contacto y del DS, lo cual determina la interacción y coalescencia entre gotas impresas para obtener películas uniformes. En este sentido, es de suma importancia medir el ángulo de contacto entre las tintas y el sustrato utilizados, lo cual aún se encuentra en proceso al presentar este manuscrito.

Por otra parte, se ha demostrado que una capa transportadora de electrones (ETL) de $\mathrm{ZnO}$, impresa por inyección piezoeléctrica de tinta y con un espesor de $40 \mathrm{~nm}$, resultó en celdas solares poliméricas de estructura invertida con una eficiencia de conversión de energía (PCE) de 7,47\% (Sánchez et al., 2018). A pesar del excelente resultado obtenido, los autores convergen en que mejorar la uniformidad de la ETL impresa podría incrementar la respuesta espectral de la celda solar. Además, se ha reportado la fabricación de transistores de película delgada (TFTs) con $\mathrm{ZnO}$ como capa activa, depositada mediante pulverización catódica, donde el desempeño de aquellos dispositivos que presentaban una mayor estabilidad y una menor corriente de fuga correspondía a los TFTs con una capa de ZnO de menor espesor (Chung et al., 2008). También, usando la técnica de IJP sólo para el depósito de la capa activa, se ha reportado la fabricación de TFTs basados en $\mathrm{ZnO}$ con un espesor de $150 \mathrm{~nm}$, los cuales presentaron características eléctricas con una movilidad por efecto de campo de $\sim 3$ $\mathrm{cm}^{2} / \mathrm{V} \cdot \mathrm{s}$ (Lim et al., 2014), donde los autores coinciden en que la morfología de la capa de $\mathrm{ZnO}$ dentro de la región del canal afectó significativamente el desempeño del transistor. De esta forma, para la impresión piezoeléctrica de la tinta comercial de $\mathrm{nP}-\mathrm{ZnO}$, la utilización de las condiciones y parámetros descritos en este estudio provee una alternativa a algunos problemas del desempeño de dispositivos semiconductores de película delgada, que previamente han sido reportados y asociados al proceso de fabricación.

Finalmente, la Tabla 4 resume las longitudes medidas experimentalmente en ambas dimensiones que delimitan el área impresa con la tinta de $\mathrm{Al}: \mathrm{ZnO}$, acorde al cuadrado diseñado y a la variación de la resolución en una dimensión. Al comparar el área diseñada con aquella impresa sólo se presentaron ligeras diferencias en ambos ejes, con una diferencia mínima de $\sim 8 \mu \mathrm{m}$ en dirección horizontal y una máxima de $\sim 97 \mu \mathrm{m}$ hacia las coordenadas verti- 
cales, donde esta última diferencia es menor que en el caso máximo de los patrones de $\mathrm{ZnO}(\sim 194 \mu \mathrm{m})$. Cabe recordar que el diámetro de la gota es de $\sim 50 \mu \mathrm{m}$, acorde a las OMs obtenidas para el patrón impreso con un DS=50 $\mu \mathrm{m}$, por lo que el depósito de las gotas de $\mathrm{Al}: \mathrm{ZnO}$ con un $\mathrm{DS}<25 \mu \mathrm{m}$ debería producir un aumento de la dimensión del patrón en dirección horizontal preferencialmente, acorde a los resultados obtenidos con la tinta de $\mathrm{ZnO}$ y al modelo propuesto por (Soltman y Subramanian, 2008). Sin embargo, las dimensiones medidas para los patrones de Al: $\mathrm{ZnO}$ mostraron un excelente ajuste entre el área impresa y aquella diseñada para cada DS seleccionado, lo cual posiblemente también esté relacionado con la diferencia en la tensión superficial de las tintas de $\mathrm{ZnO}$ y de $\mathrm{Al}: \mathrm{ZnO}$. De esta forma, las gotas que impactan sobre aquellas que ya han sido impresas y sobre la superficie del sustrato podrían presentar diferentes comportamientos; es decir, cuando una nueva gota de $\mathrm{Al}: \mathrm{ZnO}$ impacta sobre el sustrato, ésta puede fluir sobre su superficie, produciendo un ligero incremento en el diámetro de la gota impresa y una reducción tanto del ángulo de contacto como del espesor debido a una tensión superficial de $\sim 49$ $\mathrm{mJ} / \mathrm{m}^{2}$, véase la Tabla 1 . Mientras que la nueva gota de $\mathrm{Al}: \mathrm{ZnO}$, que impacta sobre una línea de gotas ya impresa, no logra propagarse e incorporarse de la misma forma hacia dicha línea para producir el aumento en la longitud del patrón impreso debido a que la tensión superficial de ambos elementos dificulta su coalescencia. Esto también coincide con la ubicación de la tinta de $\mathrm{Al}: \mathrm{ZnO}$ en el esquema de la Figura 1(b), la cual tiende ligeramente a una región donde la fuerza de capilaridad tiene mayor influencia en la propagación de la gota sobre el sustrato, en comparación con la tinta de $\mathrm{ZnO}$.

Aunque el modelo propuesto en (Soltman y Subramanian, 2008) permite explicar el incremento de la dimensión horizontal de los patrones impresos con la tinta comercial de $\mathrm{ZnO}$, éste no considera las propiedades reológicas de la tinta, por lo que no se ajusta al comportamiento observado sobre el control de la uniformidad del área impresa en los patrones de Al:ZnO. Los resultados aquí presentados proveen más información experimental para ampliar posteriormente dicho modelo y asociar las propiedades reológicas de la tinta con la interacción de una nueva gota que impacta a una línea de gotas previamente impresa, que en última instancia determina el control sobre la morfología, el espesor y la uniformidad del área en los patrones impresos mediante la técnica de inyección piezoeléctrica de tinta.

\section{Conclusiones}

Las propiedades reológicas de tintas comerciales basadas en $\mathrm{ZnO}$ y Al: $\mathrm{ZnO}$ en forma de nanopartículas (nPs) cumplen con los criterios sugeridos de imprimibilidad e interacción entre una gota expulsada que impacta la superficie de un sustrato, indicando que éstas son apropiadas para su uso en un proceso de impresión por inyección de tinta.

Operando el equipo DIMATIX en el régimen de goteo-sobredemanda se obtuvo una generación y expulsión de estas tintas libres de gotas satélite. Sin embargo, fue necesario implementar medidas que habilitaran el proceso de eyección de gotas de manera continua, uniforme, repetible y sin obstrucción de los inyectores, como: la preparación previa de las tintas y los cartuchos usados, y la configuración del equipo $\mathrm{DoD}$, destacando el diseño de la forma de onda del voltaje aplicado a la membrana piezoeléctrica, aunque esto implicara la formación de gotas satélite.

Los resultados de la morfología de los patrones impresos mostraron que es posible obtener superficies homogéneas y densas al reducir el espaciamiento entre gotas (DS) por debajo de $30 \mu \mathrm{m}$, además de gotas individuales y alineadas en ambos ejes cuando se configura un DS de $40 \mu \mathrm{m}$ para la tinta de $\mathrm{ZnO}$ y uno de $50 \mu \mathrm{m}$ para la tinta de $\mathrm{Al}: \mathrm{ZnO}$. Las mediciones realizadas por AFM exhibieron una rugosidad que depende del traslape entre gotas conforme varía el DS entre $15 \mu \mathrm{m}$ y $40 \mu \mathrm{m}$. Donde la mayor rugosidad corresponde a la impresión de gotas individuales y se atribuye a una ligera acumulación de las nPs hacia la periferia de la gota por el efecto conocido como anillo de café.

El espesor de los patrones impresos depende de su resolución y de la tensión superficial de la tinta, por lo que el comportamiento en la variación del espesor se asocia a la integración de las gotas adyacentes en ambas direcciones de impresión acorde al traslape configurado, a la obtención de superficies visiblemente homogéneas y al tamaño de las nPs de cada material. La variación del espesor de patrones impresos con $\mathrm{ZnO}$ y Al: $\mathrm{ZnO}$ fue entre $10 \mathrm{~nm}$ y $40 \mathrm{~nm}$, donde una ligera diferencia en los parámetros ópticos para determinar el espesor, en comparación a aquellos reportados en trabajos de investigación previos, se atribuye a los residuos del solvente utilizado para dispersar las nPs.

En la uniformidad del área que delimita al patrón impreso, también influye la interacción y coalescencia de gotas adyacentes, acorde al traslape producido por el DS. En este sentido, el incremento de $\sim 194 \mu \mathrm{m}$ en la dirección horizontal de los patrones de $\mathrm{ZnO}$ es consecuencia de una expansión de las dimensiones de la línea ya impresa, cuando se cumple que el DS configurado es menor que el radio de una gota independiente que impacta al sustrato. $\mathrm{El}$ área medida para los patrones de $\mathrm{Al}: \mathrm{ZnO}$ presentaron una excelente coincidencia entre el área impresa y aquella diseñada para todos los DS configurados, aunque se requiere considerar la influencia de las propiedades reológicas de la tinta sobre la interacción de una nueva gota que impacta a una línea de gotas previamente impresa. De esta forma, con el uso de las condiciones y parámetros descritos en este trabajo para la impresión por inyección piezoeléctrica de las tintas comerciales de $\mathrm{ZnO}$ y $\mathrm{Al}: \mathrm{ZnO}$ en forma de nPs, es posible mejorar las características eléctricas de dispositivos semiconductores de capa delgada que han sido reportados previamente, utilizando $\mathrm{ZnO}$ y/o $\mathrm{Al}: \mathrm{ZnO}$ impreso como parte de su estructura. Además, cabe la posibilidad de que los resultados presentados en cuanto al control de la morfología, el espesor y la uniformidad del área del patrón impreso sirvan preliminarmente para la fabricación de dispositivos semiconductores de película delgada completamente impresos.

\section{Agradecimientos}

Este trabajo fue financiado en parte por el Consejo Nacional de Ciencia y Tecnología (CONACyT) a través del Proyecto 237213 en México. Especialmente, S. I. Garduño agradece al programa del CONACyT "Cátedras CONACyT para Jóvenes Investigadores" \#CienciaBajoProtesta. J. Fajardo agradece a CONACyT por el apoyo financiero a través de la beca nacional 925402. Los autores agradecen el apoyo del Ing. Luis Abad por la preparación y limpieza de los sustratos utilizados. De igual manera, un agradecimiento a la M.C. Georgina Ramírez por las mediciones de AFM.

\section{Referencias}

Arrabito, G., et al., (2020). Printing ZnO Inks: From Principles to Devices. Crystals 10, 449, 1-34. DOI: 10.3390/cryst10060449

Carlos, E., et al., (2021). Design and synthesis of low temperature printed metal oxide memristors. Journal of Materials Chemistry C 9, 11, 39113918. DOI: 10.1039/D0TC05368F

Chang, S.J., et al., (2003). Highly reliable nitride-based LEDs with SPS+ITO upper contacts. IEEE Journal of Quantum Electronics 39, 11, 1439-1443. DOI: $10.1109 / \mathrm{JQE} .2003 .818312$

Chu, Y., et al., (2019). Printed Diodes: Materials Processing, Fabrication, and Applications. Advanced Science 6, 1-29. DOI: 10.1002/advs.201801653 
Chung, J.H., et al., (2008). Effect of thickness of $\mathrm{ZnO}$ active layer on $\mathrm{ZnO}$ TFT's characteristics. Thin Solid Films 516, 16, 5597-5601. DOI: 10.1016/j.tsf.2007.07.107

Derby, B., Reis, N., (2003). Inkjet Printing of Highly Loaded Particulate Suspensions. MRS Bulletin: Inkjet Printing of Functional Materials 28, 11, 815-818. DOI: $10.1557 / \mathrm{mrs} 2003.230$

Dong, H. M., et al., (2006). An experimental study of drop-on-demand drop formation. Physics of Fluids 18, 1-16. DOI: 10.1063/1.2217929

Dressaire, E., Sauret, A., (2017). Clogging of microfluidic systems. Soft Matter 13, 1, 37-48. DOI: 10.1039/C6SM01879C

Du, Z., et al., (2018). Inkjet printing of viscoelastic polymer inks. Chinese Chemical Letters 29, 3, 399-404. DOI: 10.1016/j.cclet.2017.09.031

Fromm, J. E., (1984). Numerical calculation of the fluid dynamics of drop-ondemand jets. IBM Journal of Research and Development 28, 3, 322-333. DOI: $10.1147 / \mathrm{rd} .283 .0322$

Fujifilm Dimatix, Inc., (2016). Dimatix Materials Printer DMP-2850 Use Manual.

Gordon, R. G., (2020). Criteria for Choosing Transparent Conductors. MRS Bulletin: Transparent Conducting Oxides 25, 8, 52-57. DOI: $10.1557 / \mathrm{mrs} 2000.151$

Gutierrez, G., et al., (2013). Fully patterned and low temperature transparent ZnO-based inverters. Thin Solid Films 545, 31, 548-461. DOI: 10.1016/j.tsf.2013.07.069

Hashemi, S. A., et al., (2020). Recent Progress in Flexible-Wearable Solar Cells for Self-Powered Electronic Devices. Energy \& Environmental Science 13, 3, 685-743. DOI: 10.1039/C9EE03046H

Kandpal, K., Gupta N., (2016). Zinc Oxide Thin Films Transistors: Advances, Challenges and Future Trends. Bulletin of EEI 5, 2, 205-212. DOI: 10.11591/eei.v5i2.634

Kern, W., (1993). Handbook of semiconductor wafer cleaning technology. Noyes Publication, Ney Jersey, USA.

Kim, G. H., et al., (2009). Formation Mechanism of Solution-Processed Nanocrystalline InGaZnO Thin Film as Active Channel Layer in Thin-Film Transistor. Journal of The Electrochemical Society 156, 1, H7-H9. DOI: $10.1149 / 1.2976027$

Krainer, S., et al., (2020). Predicting inkjet dot spreading and print through from liquid penetration- and picoliter contact angle measurement. Nordic Pulp \& Paper Research Journal 35, 1, 124-136. DOI: 10.1515/npprj-20190088

Lee, A., et al., (2012). Optimization of Experimental Parameters to Suppress Nozzle Clogging in Inkjet Printing. Industrial \& Engineering Chemistry Research 51, 40, 13195-13204. DOI: 10.1021/ie301403g

Li, Y., et al., (2017). All Inkjet-Printed Metal-Oxide Thin-Film Transistor Array with Good Stability and Uniformity Using Surface-Energy Patterns. ACS Applied Material Interfaces 9, 8194-8200. DOI: 10.1021/acsami.7b00435

Li, Y., et al., (2019). Deposited Nanoparticles Can Promote Air Clogging of Piezoelectric Inkjet Printhead Nozzles. Langmuir 35, 16, 5517-5524. DOI: 10.1021/acs.langmuir.8b04335

Lim, S. C., et al., (2014). Device characteristics of inkjet-printed ZnO TFTs by solution process. Japanese Journal of Applied Physics 53, 05HB10, 15. DOI: $10.7567 /$ JJAP.53.05HB10

Lin, X., et al., (2015). Inkjet-Printed $\mathrm{Cu}_{2} \mathrm{ZnSn}(\mathrm{S}, \mathrm{Se})_{4}$ Solar Cells. Advanced Science 2, 6, 1-6. DOI: 10.1002/advs.201500028

Liu, Y., Derby, B., (2019). Experimental study of the parameters for stable drop-on-demand inkjet performance. Physics of Fluids 31, 3, 1-11. DOI: 10.1063/1.5085868

Mampallil, D., Eral, H. B., (2018). A review on suppression and utilization on the coffee-ring effect. Advances in Colloid and Interface Science 252, 3854. DOI: $10.1016 /$ j.cis.2017.12.008
Martin, G. D., et al., (2008). Inkjet printing-the physics of manipulating liquid jets and drops. Journal of Physics: Conference Series 105, 1-14. DOI: 10.1088/1742-6596/105/1/012001

Matavž, A., Malič, B., (2018). Inkjet printing of functional oxide nanostructures from solution-based inks. Journal of Sol-Gel Science and Technology 87, 1-21. DOI: 10.1007/s10971-018-4701-3

Nahlik, J., et al., (2019). A High Sensitivity UV Photodetector With Inkjet Printed $\mathrm{ZnO}$ /Nanodiamond Active Layers. IEEE Sensors Journal 19, 14, 5587-5593. DOI: 10.1109/JSEN.2019.2893572

Ning, H., et al., (2017). Direct Inkjet Printing of Silver Source/Drain Electrodes on an Amorphous InGaZnO Layer for Thin-Film Transistors. Materials 10, 51, 1-7. DOI: 10.3390/ma10010051

Notz, P. K., Basaran, O. A., (2004). Dynamics and breakup of a contracting liquid filament. Journal of Fluid Mechanics 512, 223-256. DOI: 10.1017/S0022112004009759

Park, J. W., et al., (2019). A Review of Low-Temperature Solution-Processed Metal Oxide Thin-Film Transistors for Flexible Electronics. Advanced Functional Materials 1904632, 1-40. DOI: 10.1002/adfm.201904632

Sacramento, A., et al., (2020). Inverted Polymer Solar Cells Using Inkjet Printed $\mathrm{ZnO}$ as Electron Transport Layer: Characterization and Degradation Study. IEEE Journal of the Electron Devices Society 8, 413-420. DOI: 10.1109/JEDS.2020.2968001

Sanchez, J. G., et al., (2018). Impact of inkjet printed $\mathrm{ZnO}$ electron transport layer on the characteristics of polymer solar cells. RSC Advances 8, 24, 13094-13102. DOI: 10.1039/c8ra01481g

Schiaffino, S., Sonin, A. A., (1997). Molten droplet deposition and solidification at low Weber numbers. Physics of Fluids 9, 11, 3172-3187. DOI: $10.1063 / 1.869434$

Secor, E. B., et al., (2016). High-Performance Inkjet-Printed Indium-GalliumZinc-Oxide Transistors Enabled by Embedded, Chemically Stable Graphene Electrodes. ACS Applied Material Interfaces 8, 17428-17434. DOI: 10.1021/acsami.6b02730

Sigma-Aldrich, (2021). Aluminum-doped zinc oxide nanoparticle ink. Ficha de datos de seguridad, disponible en: https://www.sigmaaldrich.com

Sigma-Aldrich, (2021). Zinc oxide nanoparticle ink. Ficha de datos de seguridad, disponible en: https://www.sigmaaldrich.com

Soltman, D., Subramanian, V., (2008). Inkjet-printed line morphologies and temperature control of the coffee ring effect. Langmuir 24, 5, 2224-2231. DOI: $10.1021 / 1 \mathrm{a} 7026847$

Song, K., et al., (2010). Fully Flexible Solution-Deposited Thin-Film Transistors. Advanced Materials 22, 38, 4308-4312. DOI: 10.1002/adma.201002163

Sowade, E., et al., (2016). All-inkjet-printed thin-film transistors: manufacturing process reliability by root cause analysis. Scientific Reports 6, 33490, 1-15. DOI: $10.1038 /$ srep33490

Stelling, C., et al., (2017). Plasmonic nanomeshes: their ambivalent role as transparent electrodes in organic solar cells. Scientific Reports 7, 1, 1-13. DOI: $10.1038 /$ srep 42530

Treharne, R. E., et al., (2011). Optical design and fabrication of fully sputtered $\mathrm{CdTe} / \mathrm{CdS}$ colar cells. Journal of Physics: Conference Series 286, 1-8. DOI: $10.1088 / 1742-6596 / 286 / 1 / 012038$

Vernieuwe, K., et al., (2017). Thermal processing of aqueous AZO inks towards functional TCO thin films. Journal os Alloys and Compounds 690 , 5, 360-368. DOI: 10.1016/j.jallcom.2016.08.120

Wang, N.-F., et al., (2013). Effect of surface texture on Al-Y codoped $\mathrm{ZnO} / \mathrm{n}$ Si heterojunction solar cells. IEEE Transactions on Electron Devices 60, 12, 4073-4078. DOI: 10.1109/TED.2013.2287060 